Theoretical investigation of interaction of hydrogen and intermetallic compound YCo5

J. Radaković ${ }^{1}$, K. Batalović ${ }^{1}$, A. Umićević ${ }^{1}$, G.I. Miletić ${ }^{2, *}$

${ }^{1}$ Institute for nuclear sciences "Vinča", University of Belgrade, Belgrade, Serbia

${ }^{2}$ Laboratory for Solid State and Complex Compounds Chemistry, Division of Materials

Chemistry, Ruđer Bošković Institute, P.O. Box 180, 10002 Zagreb, Croatia

*Corresponding author: G. I. Miletić; e-mail: gmiletic@irb.hr; Tel.: +385 14561 111; fax: +385 14680084. 


\begin{abstract}
Stability, magnetic properties, electric field gradients and hyperfine fields of $\mathrm{YCo}_{5} \mathrm{H}_{\mathrm{x}}$ compounds were investigated by using DFT based calculations. Two computational approaches were employed employed in the study-ultrasoft pseudopotentials with plane waves and all-electron FP(L)APW + lo method.

It was found that $\mathrm{H}$ atoms prefer off-centered or centered octahedral sites. Enthalpies of formation for $\alpha \rightarrow \beta$ transition were calculated. Satisfactory agreement was found between theoretical results and previous experimental value of the enthalpy of formation. It was also found that inclusion of spin-polarization reduces stability of the hydrides.

Comparison of theoretical and experimental spin magnetic moments of different $\mathrm{YCo}_{5} \mathrm{H}_{\mathrm{x}}$ compounds resulted in a reasonable agreement betwen present theoretical results and previous experimental and theoretical data. Magnetocrystalline anisotropy energy (MAE) was calculated for intermetallic compound $\mathrm{YCo}_{5}$. Reasonable agreement was found between MAE obtained in the present study and the corresponding theoretical and experimental values obtained in earlier studies.
\end{abstract}

\title{
Keywords:
}

DFT calculations; Intermetallics; Metal hydrides; Enthalpy; Electronic properties; Magnetism

A. intermetallics; A. metal hydrides; A. magnetically ordered materials; C. electronic band structure; C. electronic properties; C. enthalpy 


\section{Theoretical investigation of interaction of hydrogen and intermetallic compound $\mathrm{YCo}_{5}$}

\section{Introduction}

Efficient storage of energy is one of the main prerequisites for use of clean energy sources in fossil fuel independent economy. One of the main energy carriers is hydrogen and one of the potential media for storage of hydrogen are metal hydrides, compounds formed between hydrogen and some metal or intermetallic compound [1].

Among different crystal structure types available for realization of crystal structures of intermetallic compounds, hexagonal Haucke type $\left(\mathrm{CaCu}_{5}\right.$ structure type; space group $\left.\mathrm{P} 6 / \mathrm{mmm}\right)$ intermetallic compounds provide important class of compounds for hydrogen storage with $\mathrm{LaNi}_{5}$ as the best known representative. Many different intermetallic compounds isostructural to $\mathrm{CaCu}_{5}$ were investigated as possible hydrogen storage media. Other well known representative of the hexagonal Haucke compounds is $\mathrm{SmCo}_{5}$, a material which exhibits important magnetic properties [2].

In this work we present results of theoretical investigation of $\mathrm{YCo}_{5} \mathrm{H}_{\mathrm{x}}$ compounds $(\mathrm{x}=0.0$, $0.25,0.5,1.0,3.0,3.5,4.0)$ to investigate different aspects of interaction of hydrogen with hexagonal Haucke compound $\mathrm{YCo}_{5}$ - stability of different hydride phases and influence of hydrogen on magnetic properties, electric field gradients and hyperfine fields. 


\section{Computational details}

Initial set of structures was optimized by using implementation of density functional theory (DFT) in the Quantum ESPRESSO package [3].

For calculation of the exchange-correlation energy generalized gradient approximation (GGA) was employed [4,5].

Plane-wave (PW) basis set with ultrasoft (US) pseudopotentials (PP) [6,7] was employed. Plane-wave cutoff for expansion of wavefunctions was 35.0 Ry. For expansion of charge density and potential plane-wave cutoff was set to $350.0 \mathrm{Ry}$.

The first set of geometry optimizations of $\mathrm{YCo}_{5} \mathrm{H}_{\mathrm{x}}$ compounds was performed with nonspin-polarized (NSP) calculations. $8 \times 8 \times 8$ k-point meshes for Brillouin zone (BZ) sampling were used for basic unit cells (i.e. hexagonal $\mathrm{CaCu}_{5}$-like unit cells containing one $\mathrm{YCo}_{5}$ formula unit). For multiple hexagonal $\mathrm{CaCu}_{5}$-like unit cells k-point meshes were appropriately reduced. Geometries obtained in the first step were used in the second set of geometry optimizations as input. In this step spin-polarized (SP) calculations were used for geometry optimizations. $12 \times 12 \times 12$ k-point meshes were employed for hexagonal $\mathrm{CaCu}_{5}$-like unit cells and appropriately reduced k-point meshes were used for multiple hexagonal-like unit cells. For geometry optimizations of other types of unit cells (e.g. orthorhombic) analogous procedure was used.

Marzari-Vanderbilt cold smearing scheme [8] was employed for Brillouin zone integrations with broadening of $0.01 \mathrm{Ry}$.

For optimization of interatomic distance of $\mathrm{H}_{2}$ molecule cubic unit cell with dimensions 20.0 a.u. $\times 20.0$ a.u. $\times 20.0$ a.u. containing one $\mathrm{H}_{2}$ molecule was used and calculations were performed at $\boldsymbol{\Gamma}$-point of the BZ. 
Enthalpy of formation $\left(\Delta \mathrm{H}\right.$ or $\Delta \mathrm{H}_{\mathrm{x} 1 \rightarrow \mathrm{x} 2}$ ) is calculated as the difference between total energies of products and reactants, i.e. for reaction $\mathrm{A}+\mathrm{B} \rightarrow \mathrm{C}, \Delta \mathrm{H}$ is given as $\Delta \mathrm{H}=\mathrm{E}(\mathrm{C})-(\mathrm{E}(\mathrm{A})+$ $\mathrm{E}(\mathrm{B}))$ where $\mathrm{E}(\mathrm{X})$ is the total energy of species $\mathrm{X} . \Delta \mathrm{H}_{\mathrm{x} 1 \rightarrow \mathrm{x} 2}$ corresponds to the following chemical reaction [9]: $2 /\left(\mathrm{x}_{2}-\mathrm{X}_{1}\right) \mathrm{YCo}_{5} \mathrm{H}_{\mathrm{x} 1}+\mathrm{H}_{2} \rightarrow 2 /\left(\mathrm{x}_{2}-\mathrm{X}_{1}\right) \mathrm{YCo}_{5} \mathrm{H}_{\mathrm{x} 2}$.

Additional set of calculations was performed using all-electron full-potential (linearized) augmented plane-wave (FP(L)APW) + local orbitals (lo) method, as implemented in DFT package WIEN2k [10]. This additional set of calculations was performed to study electric field gradients (EFG), hyperfine fields and to provide additional details on magnetic properties of the studied compounds.

The selected radii of the muffin-tin spheres, centered on the atomic nuclei, $\left(R_{m t}\right)$ were set to $2.2 \mathrm{bohr}$ for $\mathrm{Y}, 2.0 \mathrm{bohr}$ for $\mathrm{Co}$, and $0.9 \mathrm{bohr}$ for $\mathrm{H}$. The number of basis functions used in the interstitial region was tested with respect to all calculated physical values in pure $\mathrm{YCo}_{5}$, as well as in its hydrides. It was determined by $R_{m t} K_{\max }$ parameter, which was set to 4.5 for hydride calculations and 8.5 for $\mathrm{YCo}_{5}$ calculations. Inside the muffin-tin spheres the wave functions were expanded in spherical harmonics up to $l_{\max }=10$. In order to include the low-lying $3 \mathrm{~s}$ states of Co, the cut-off energy that separated the core and valence states equalled $-8.0 \mathrm{Ry}$. All calculations were spin-polarized, and spin-orbit interaction on $3 \mathrm{~d}$ orbitals of Co was also included. For the purpose of calculating the magnetocrystalline anisotropy energy (MAE) in $\mathrm{YCo}_{5}$ the magnetization direction was parallel to $\mathrm{z}$ or $\mathrm{x}$ axis of the unit cell. For other calculations that included spin-orbit coupling magnetization direction was parallel to $\mathrm{z}$ axis. The exchange and correlation effects were included within the generalized gradient approximation (GGA) using the Perdew-Burke-Ernzerhof (PBE) scheme [4,5]. Brillouin zone integration was performed via the tetrahedron method, and a well-converged mesh of $440 \mathbf{~ k}$ points was used in the irreducible Brillouin zone (IBZ) of $\mathrm{YCo}_{5}$, while for hydrides a number of IBZ $\mathbf{k}$ points ranged from 256 to 
462. Self-consistency was achieved by demanding that the difference of integrated charge in successive iterations was less than $10^{-5}$ e. Relaxation of all atomic positions was performed where necessary until forces acting on all atoms were less than $1 \mathrm{mRy} / \mathrm{bohr}$.

\section{Results and Discussion}

\subsection{Site preference of $\mathrm{H}$ atoms and formation of $\alpha$-phase}

At first the site preference of $\mathrm{H}$ atoms for the available interstitial positions in $\mathrm{YCo}_{5}$ was investigated. Initial coordinates of interstitial positions were taken from experiment [11] and they are provided in Table 1. Corresponding enthalpies of formation are provided in Table 2 and Table 3. From Table 2 and Table 3 follows that stability of hydrides decreases with the inclusion of spin-polarization. Slightly off-centered octahedral $12 \mathrm{n}$ site is the most stable with octahedral $3 \mathrm{f}$ position being very close or (within given precision) identical in energy. This is in agreement with the fact that $12 \mathrm{n}$ site is obtained by slight off-centering of the $3 \mathrm{f}$ position. In the previous experimental and theoretical work on isostructural compounds (see [12] and references therein) it was also found that $12 \mathrm{n}$ position is the most stable interstitial site.

To assess the stability of $\alpha$ solid solution, calculations were also performed for composition $\mathrm{x}=0.25$. Compositions $\mathrm{x}=0.25$ and $\mathrm{x}=0.5$ were modeled with $2 \times 2 \times 1$ and $1 \times 1 \times 2$ supercells, respectively. Accordingly to the results presented above, for $\mathrm{x}=0.25$ composition $\mathrm{H}$ atom was placed in the $12 \mathrm{n}$ position. Results are given in Table 4 and, in agreement with results given above, they indicate lowering of the stability of hydride phases with the inclusion of spinpolarization. 
Single phase region of the $\alpha$ phase extends approximately in the region of $0.0 \leq \mathrm{x} \leq 0.5$ [13]. Calculated values of $\Delta \mathrm{H}$ for $\mathrm{x}=0.25$ and $\mathrm{x}=0.5$ obtained from NSP calculations exhibit large difference. On the other hand, SP calculations resulted in, within given precision, identical values for the two compositions $(-7.4 \mathrm{~kJ} /(\mathrm{mol} \mathrm{H})$ for both $\mathrm{x}=0.25$ and $\mathrm{x}=0.5$, respectively). These two values could be regarded as values that represent the enthalpy of formation of the $\alpha$ phase.

\section{$3.2 \alpha \rightarrow \beta$ transition}

Two phase $\alpha-\beta$ region in the $\mathrm{YCo}_{5}-\mathrm{H}_{2}$ system extends approximately in the interval $0.5 \leq \mathrm{x} \leq 3.0$ while single phase region of the $\beta$ phase extends in the approximate interval $x \geq 3.0$ [13].

Two structural models were employed to model the $\beta$-phase in the $\mathrm{YCo}_{5}-\mathrm{H}_{2}$ system. It is assumed that $\beta$-phase could be isostructural to the crystal structures of $\beta^{\mathrm{I}}-\mathrm{LaCo}_{5} \mathrm{D}_{3.35}$ or $\beta^{\mathrm{III}}$ $\mathrm{CeCo}_{5} \mathrm{D}_{2.55}$ phase that were obtained from neutron diffraction experiments [14]. Crystal structure data for the two phases as obtained in reference [14] are given in Table 5 and Table 6, respectively. Enthalpies of formation for $\alpha \rightarrow \beta$ transition obtained from NSP calculations are given in Table 7 together with the experimental value obtained in reference [13]. All values provided in Table 7 are lower than the experimental value [13]. Probably the closest hydrogen contents for $\alpha$ and $\beta$ phases would be, respectively, $x_{1}=0.25,0.5$ and $x_{2}=3.0,3.5$.

It should be noted that, when $\beta^{\mathrm{I}}-\mathrm{LaCo}_{5} \mathrm{D}_{3.35}$ phase is used as a structural model, $\mathrm{x}_{2}=3.0$, 3.5 compositions are modeled with, respectively, primitive and conventional unit cell of $\beta^{\mathrm{I}}$ $\mathrm{LaCo}_{5} \mathrm{D}_{3.35}$ phase with one $\mathrm{H}$ atom removed. Since there are two crystallographic positions (4e and $4 \mathrm{~h}$ ) accommodating $\mathrm{H}$ atoms in the case of $\beta^{\mathrm{I}}-\mathrm{LaCo}_{5} \mathrm{D}_{3.35}$ phase, relative stability of the two possible cases should be explored. For both $\mathrm{x}_{2}=3.0$ and $\mathrm{x}_{2}=3.5$ compositions, structure with one $\mathrm{H}$ 
atom removed from the $4 \mathrm{e}$ site is more stable the energy differences being, respectively, 10.4 and $5.9 \mathrm{~kJ} /\left(\mathrm{mol} \mathrm{YCo}_{5}\right)$. Structures with higher stability were then used for calculation of enthalpies of formation given in Table 7.

From the comparison of $\Delta \mathrm{H}$ corresponding to the $\beta^{\mathrm{I}}-\mathrm{LaCo}_{5} \mathrm{D}_{3.35}$ and $\beta^{\mathrm{III}}-\mathrm{CeCo}_{5} \mathrm{D}_{2.55}$ based structures for the same composition it can be concluded that the $\beta^{\mathrm{III}}-\mathrm{CeCo}_{5} \mathrm{D}_{2.55}$ based structures are more stable than $\beta^{\mathrm{I}}-\mathrm{LaCo}_{5} \mathrm{D}_{3.35}$ based structures.

$\Delta \mathrm{H}$ values for compositions $\mathrm{x}_{1}=0.25,0.5$ ( $\alpha$-phase) and $\mathrm{x}_{2}=3.0,3.5$ ( $\beta$-phase) span range from -21.4 to $-17.4 \mathrm{~kJ} /(\mathrm{mol} \mathrm{H})$. After comparing these values to the experimental value of -15.2 $\mathrm{kJ} /(\mathrm{mol} \mathrm{H})$ [13] it can be concluded that NSP calculations underestimate enthalpy of formation for $\alpha \rightarrow \beta$ transition.

Enthalpies of formation for $\alpha \rightarrow \beta$ transition acquired from SP calculations are provided in Table 8. Experimental value obtained in reference [13] is also provided in Table 8. According to the Table 7 and Table 8, in agreement with the above results, introduction of spinpolarization results in higher values of enthalpies of formation for the $\alpha \rightarrow \beta$ transition.

Similarly to the above NSP results, it is more favorable to remove $\mathrm{H}$ atom from the $4 \mathrm{e}$ position of, respectively, primitive and conventional unit cell of $\beta^{\mathrm{I}}-\mathrm{LaCo}_{5} \mathrm{D}_{3.35}$ structure to reach compositions $\mathrm{x}_{2}=3.0,3.5$. Corresponding energy differences are, respectively, 24.9 and 12.2 $\mathrm{kJ} /\left(\mathrm{mol} \mathrm{YCo}_{5}\right)$. As in the above case of NSP results, structures with higher stabilities were employed to obtain enthalpies of formation provided in Table 8.

In agreement with the above NSP results, $\beta^{\mathrm{III}}-\mathrm{CeCo}_{5} \mathrm{D}_{2.55}$ based structures are more stable than $\beta^{\mathrm{I}}-\mathrm{LaCo}_{5} \mathrm{D}_{3.35}$ based structures with the same hydrogen content.

Values of enthalpies of formation as obtained from the present SP calculations (Table 8) for $\alpha \rightarrow \beta$ transition for compositions $\mathrm{x}_{1}=0.25,0.5$ ( $\alpha$-phase) and $\mathrm{x}_{2}=3.0,3.5$ ( $\beta$-phase) span 
interval from -13.6 to $-11.2 \mathrm{~kJ} /(\mathrm{mol} \mathrm{H})$ while corresponding experimental value amounts to -15.2 $\mathrm{kJ} /(\operatorname{mol} \mathrm{H})$ [13]. It can be, therefore, concluded that present $\mathrm{SP}$ results to some extent overestimate enthalpy of formation for the $\alpha \rightarrow \beta$ transition.

\subsection{Magnetic properties}

\subsubsection{US-PP-PW results}

Spin magnetic moments $\left(\mathrm{M}_{\mathrm{s}}\right)$ for the investigated $\mathrm{YCo}_{5} \mathrm{H}_{\mathrm{x}}$ compounds are given in Table 9. In the case of structures with composition $x=3.0,3.5$ based on $\beta^{\mathrm{I}}-\mathrm{LaCo}_{5} \mathrm{D}_{3.35}$ structure, in agreement with the results provided above, spin magnetic moments of structures with higher stability are given in Table 9 .

From the comparison of the presently obtained theoretical values and experimental values [15] follows that theory slightly underestimates the values of magnetic moments in the case of $\mathrm{YCo}_{5}$ and models for $\alpha$-phase while there is a certain overestimation of magnetic moments for the $\beta$-phase. Present theoretical results are in a reasonable agreement with previous theoretical results in the case of $\mathrm{YCo}_{5}$ [16-18]. It should be noted that present US-PP-PW calculations deliver only spin magnetic moments and that the contribution from orbital moments is absent. This could, to some extent, explain why present US-PP-PW calculations underestimate magnetic moments for $\mathrm{YCo}_{5}$ and models of $\alpha$-phase. On the other hand, the reason for overestimation of magnetic moments of $\beta$-phase is not known at present. 


\subsubsection{FP(L)APW + lo results}

Calculation of $\mathrm{YCo}_{5}$ magnetocrystalline anisotropy energy required the inclusion of spin-orbit interaction on $3 \mathrm{~d}$ orbitals of both unequivalent Co sites. Magnetization axes parallel to (001) and (100) directions, for which the energy difference is calculated, are chosen based on the previous studies [17]. Calculated value equaled to $2.45 \mathrm{meV} \mathrm{f.u}^{-1}$, which is, compared to the previous first principles studies [17], significant improvement with respect to the experimental value of 3.8 meV f.u. ${ }^{-1}$. The observed discrepancy might be, but not necessarily, due to different lattice parameters.

In Table 10 are presented values of total spin magnetic moment $\left(\mathrm{M}_{\mathrm{s}}\right)$ per formula unit of $\mathrm{YCo}_{5} \mathrm{H}_{\mathrm{x}}$ compounds calculated in the present study. Comparison with previous first principles and experimental studies is provided where possible. The absorption of hydrogen up to three atoms per unit cell is accompanied by nearly linear decrease of $\mathbf{M}_{\mathrm{s}}$, which is consistent with present US-PP-PW results and experimentally observed trend [15]. On the other hand, further hydrogen uptake almost linearly increases the total spin magnetic moment again in agreement with present US-PP-PW results and experiment [15]. These results indicate that the absorption of hydrogen significantly modifies the electronic structure of the initial compound. Presumably, in order to form a chemical bond, hydrogen 1 s orbitals interact with $3 \mathrm{~d}$ electrons of cobalt atoms, changing the electronic charge distribution and, consequently, their magnetic properties.

Having in mind that the total spin magnetic moment of $\mathrm{YCo}_{5}$, and presumably of its hydrides, is attributed to the magnetic moments of unequivalent Co sites $\left(\mu_{s}^{C o}\right)$, we have 
calculated the spin magnetic moment projected on Co-2c and Co-3g atoms. Results are presented in Table 11 and, where possible, compared with the experimental and/or theoretical data.

According to the previous experimental [19] and theoretical [17],[19],[16] work, there is a certain contribution from orbital moments of $3 \mathrm{~d}$ states to the magnetic moments of Co atoms in $\mathrm{YCo}_{5}$. Consequently, spin-orbit coupling is included in the present calculations and calculated orbital moments are provided in Table 12. From the results for $\mathrm{YCo}_{5}$ as given in Table 12 follows that GGA functional underestimates orbital moments what is a well known feature of GGA (and LDA) (e.g. [17]). Depending on the hydrogen content, average orbital moments on Co atoms can be found in interval of $0.06-0.11 \mu_{\mathrm{B}}$.

\subsection{Electric field gradients and hyperfine fields of $\mathrm{YCo}_{5} \mathrm{H}_{x}$}

In addition to calculating the magnetic properties of studied compounds, we have also obtained the electric field gradient (EFG) and anisotropy parameter $(\eta)$ on $\mathrm{Y}$, and both unequivalent Co sites in pure $\mathrm{YCo}_{5}$, as well as its hydrides. Corresponding results are presented in Table 13.

EFG is determined by the electronic charge distribution of the selected atom, and by the spatial distribution of its neighbouring atoms. It originates from the charge density deviation from spherical symmetry in the vicinity of observed nucleus, and it is extremely sensitive to even trivial changes in the electronic structure. ${ }^{1}$ Consequently, EFG directly reflects both geometrical and electronic aspects of the studied system, and provides information on the modifications in the electronic structure induced after hydrogenation. Furthermore, anisotropy parameter contains

\footnotetext{
${ }^{1}$ It is designated as a traceless, symmetric second rank tensor, diagonal in the principle-axis coordinate system, and it is always present at the atomic site with the noncubic point group symmetry. According to the convention, its three nonzero components are ordered as $\left|V_{z z}\right| \geq\left|V_{y y}\right| \geq\left|V_{x x}\right|$; however, it is completely described by its largest component $\left(V_{z Z}^{\text {tot }}\right)$, comparable with the experimental values.
} 
information on the symmetry of the atomic site. From Table 13 it can be observed that low concentrations of the absorbed hydrogen $(\mathrm{x}<1 \mathrm{H} / \mathrm{f} . \mathrm{u}$.) do not significantly modify the local electronic structure of its neighbours; $\mathrm{V}_{\mathrm{zz}}{ }^{\text {tot }}$ of the individual atoms $\mathrm{Y}, \mathrm{Co}-2 \mathrm{c}$, and Co-3g in $\mathrm{YCo}_{5} \mathrm{H}_{\mathrm{x}}$ do not considerably differ from those in YCo5. At higher hydrogen concentrations EFG deviates from the initial values, and it also changes the sign in the case of $\mathrm{Y}$ and Co-2c, indicating considerable modifications of the local electronic structure of these atoms.

In Table 14 are presented hyperfine fields calculated on $\mathrm{Y}$ and both Co sites in pure and hydrogenated $\mathrm{YCo}_{5}$. A large variety of measured hyperfine fields in $\mathrm{YCo}_{5}$ exist in the literature [18], which is why their comparison with presently calculated ones is rather inconclusive.

\section{Conclusion}

DFT calculations were performed on the $\mathrm{YCo}_{5} \mathrm{H}_{\mathrm{x}}$ compounds using two computational approaches: US-PP-PW and FP(L)APW + lo.

Calculated properties included energetics of hydride formation, magnetic properties, electric field gradients and hyperfine fields.

Comparison of results obtained from NSP and SP calculations indicates that inclusion of spin-polarization decreases stability of the hydride phases.

Five interstitial positions were explored to investigate the site preference of $\mathrm{H}$ atoms and it was found that slightly off-centered octahedral $12 \mathrm{n}$ site is the most stable site with octahedral 3f site either very close in energy or even (within given precision) of the same stability. The highest stability of $12 \mathrm{n}$ site is in agreement with previous theoretical and experimental results on isostructural compounds. 
$\alpha \rightarrow \beta$ transition was investigated and obtained values of enthalpy of formation of $\beta$ phase from $\alpha$ phase and hydrogen were compared with the experimental value.

$\beta$ phase was modeled under assumption of isostructurality with previously determined crystal structures of $\beta^{\mathrm{I}}-\mathrm{LaCo}_{5} \mathrm{D}_{3.35}$ or $\beta^{\mathrm{III}}-\mathrm{CeCo}_{5} \mathrm{D}_{2.55}$ phases.

It was found that NSP calculations underestimate enthalpy of formation for $\alpha \rightarrow \beta$ transition with possible interval of values being $15-41 \%$ too low compared to the experimental value.

Inclusion of spin-polarization results in overestimation of enthalpy of formation of the $\beta$ phase in the $\alpha \rightarrow \beta$ transition. Possible interval of values amounts to 74-90\% of the experimental value of enthalpy of formation.

Spin magnetic moments of $\mathrm{YCo}_{5} \mathrm{H}_{\mathrm{x}}$ compounds were also calculated and compared to the experimental values and reasonable agreement was found between the theory and experiment.

In the case of $\mathrm{YCo}_{5}$ compound, presently calculated magnetic moments are found to be in reasonable agreement with previous theoretical values. Orbital moments were also calculated and it was shown that there is a certain contribution from orbital moments of $3 \mathrm{~d}$ states and that GGA, in agreement with the literature, underestimates orbital moments.

Magnetocrystalline anisotropy energy is calculated for $\mathrm{YCo}_{5}$ and a reasonable agreement with previous experimental and theoretical results was obtained.

\section{Acknowledgment}

Part of calculations in this work have been done using the Quantum ESPRESSO package [3]. 
Computational resources were provided by the Isabella cluster (isabella.srce.hr) at the Zagreb University Computing Centre (Srce).

The support for this research from the Ministry of Science, Education and Sport of the Republic of Croatia under Project no. 098-0982904-2941 is highly appreciated by G.I.M.

J.R., K.B. and A.U. would like to acknowledge the help of the Serbian Ministry of Science and Education, under Grant no. ON171001.

\section{Bibliography:}

[1] B. Sakintuna, F. Lamaridarkrim, M. Hirscher, Metal hydride materials for solid hydrogen storage: A review $\downarrow$, Int. J. Hydrog. Energy. 32 (2007) 1121-1140. doi:10.1016/j.ijhydene.2006.11.022.

[2] H.R. Kirchmayr, Permanent magnets and hard magnetic materials, J. Phys. Appl. Phys. 29 (1996) 2763-2778. doi:10.1088/0022-3727/29/11/007.

[3] P. Giannozzi, S. Baroni, N. Bonini, M. Calandra, R. Car, C. Cavazzoni, D. Ceresoli, G.L. Chiarotti, M. Cococcioni, I. Dabo, A. Dal Corso, S. de Gironcoli, S. Fabris, G. Fratesi, R. Gebauer, U. Gerstmann, C. Gougoussis, A. Kokalj, M. Lazzeri, L. Martin-Samos, N. Marzari, F. Mauri, R. Mazzarello, S. Paolini, A. Pasquarello, L. Paulatto, C. Sbraccia, S. Scandolo, G. Sclauzero, A.P. Seitsonen, A. Smogunov, P. Umari, R.M. Wentzcovitch, QUANTUM ESPRESSO: a modular and open-source software project for quantum simulations of materials, J. Phys. Condens. Matter. 21 (2009) 395502. doi:10.1088/0953-8984/21/39/395502.

[4] J.P. Perdew, K. Burke, M. Ernzerhof, Generalized Gradient Approximation Made Simple, Phys. Rev. Lett. 77 (1996) 3865-3868. doi:10.1103/PhysRevLett.77.3865.

[5] J.P. Perdew, K. Burke, M. Ernzerhof, Generalized Gradient Approximation Made Simple [Phys. Rev. Lett. 77, 3865 (1996)], Phys. Rev. Lett. 78 (1997) 1396-1396. doi:10.1103/PhysRevLett.78.1396. 
[6] D. Vanderbilt, Soft self-consistent pseudopotentials in a generalized eigenvalue formalism, Phys. Rev. B. 41 (1990) 7892-7895. doi:10.1103/PhysRevB.41.7892.

[7] We used the pseudopotentials Y.pbe-nsp-van.UPF, Co.pbe-nd-rrkjus.UPF and H.pberrkjus.UPF from http://www.quantum-espresso.org., n.d.

[8] N. Marzari, D. Vanderbilt, A. De Vita, M.C. Payne, Thermal Contraction and Disordering of the Al(110) Surface, Phys. Rev. Lett. 82 (1999) 3296-3299. doi:10.1103/PhysRevLett.82.3296.

[9] J. Murray, M. Post, J. Taylor, The thermodynamics of the system $\mathrm{CaNi}_{5}-\mathrm{H}_{2}$ using differential heat conduction calorimetry, J. Common Met. 90 (1983) 65-73. doi:10.1016/00225088(83)90117-0.

[10] P. Blaha, K. Schwarz, G. K. H. Madsen, D. Kvasnicka and J. Luitz, WIEN2k, An Augmented Plane Wave + Local Orbitals Program for Calculating Crystal Properties (Karlheinz Schwarz, Techn. Universitat Wien, Austria), 2001. ISBN 3-9501031-1-2, n.d.

[11] A. Percheron-Guégan, C. Lartigue, J.. Achard, P. Germi, F. Tasset, Neutron and X-ray diffraction profile analyses and structure of $\mathrm{LaNi}_{5}, \mathrm{LaNi}_{5-\mathrm{x}} \mathrm{Al}_{\mathrm{x}}$ and $\mathrm{LaNi}_{5-\mathrm{x}} \mathrm{Mn}_{\mathrm{x}}$ intermetallics and their hydrides (deuterides), J. Common Met. 74 (1980) 1-12. doi:10.1016/0022-5088(80)900636.

[12] G.I. Miletić, A. Drašner, DFT study of the cohesive and structural properties of $\mathrm{YNi}_{5} \mathrm{H}_{\mathrm{x}}$ compounds, J. Alloys Compd. 622 (2015) 1041-1048. doi:10.1016/j.jallcom.2014.10.106.

[13] S. Mitrokhin, T. Zotov, E. Movlaev, V. Verbetsky, Synthesis and properties of $\mathrm{AB}_{5}$-type hydrides at elevated pressures, J. Alloys Compd. 446-447 (2007) 603-605. doi:10.1016/j.jallcom.2006.12.029.

[14] F.A. Kuijpers, B.O. Loopstra, A neutron-diffraction study on the structural relationships of RCo 5 hydrides, J. Phys. Chem. Solids. 35 (1974) 301-306. doi:10.1016/S00223697(74)80022-3.

[15] M. Yamaguchi, T. Ohta, T. Katayama, Effect of hydrogen absorption on magnetic properties of $\mathrm{GdCo}_{5}$ and $\mathrm{YCo}_{5}$, J. Magn. Magn. Mater. 31-34 (1983) 221-222. doi:10.1016/0304-8853(83)90224-X.

[16] L. Nordström, O. Eriksson, M.S.S. Brooks, B. Johansson, Theory of ferromagnetism in $\mathrm{CeCo}_{5}$, Phys. Rev. B. 41 (1990) 9111-9120. doi:10.1103/PhysRevB.41.9111.

[17] P. Larson, I.I. Mazin, Calculation of magnetic anisotropy energy in $\mathrm{YCo}_{5}$, J. Magn. Magn. Mater. 264 (2003) 7-13. doi:10.1016/S0304-8853(03)00130-6. 
[18] G.H.O. Daalderop, P.J. Kelly, M.F.H. Schuurmans, Magnetocrystalline anisotropy of Y $\mathrm{Co}_{5}$ and related RECo 5 compounds, Phys. Rev. B. 53 (1996) 14415-14433.

doi:10.1103/PhysRevB.53.14415.

[19] H. Takahashi, S. Ohtsuka, T. Ukai, N. Mori, On the orbital moment of Co in $\mathrm{YCo}_{5}, \mathrm{~J}$. Magn. Magn. Mater. 70 (1987) 189-190. doi:10.1016/0304-8853(87)90401-X.

[20] P. Villars (Ed.), Pearson's Handbook Desk Edition; Crystallographic Data for Intermetallic Phases (Vol. 1), ASM International, 1997.

[21] A. Heidemann, D. Richter, K.H.J. Buschow, Investigation of the hyperfine fields in the compounds $\mathrm{LaCo}_{13}, \mathrm{LaCo}_{5}, \mathrm{YCo}_{5}$ and $\mathrm{ThCo}_{5}$ by means of inelastic neutron scattering, Z. Für Phys. B Condens. Matter Quanta. 22 (1975) 367-372. doi:10.1007/BF01312807.

[22] B. Szpunar, Density of states and magnetic properties of $\mathrm{YCo}_{5}$ and $\mathrm{Y}_{2} \mathrm{Co}_{17}$ compounds, Phys. BC. 130 (1985) 29-33. doi:10.1016/0378-4363(85)90174-3. 


\section{Tables:}

Table 1 Positions of metal atoms and interstitial positions in $\mathrm{CaCu}_{5}$ type of structure obtained from $\mathrm{x}$-ray and neutron diffraction [11].

\begin{tabular}{|c|ccc|} 
& \multicolumn{4}{|c|}{$\mathrm{CaCu}_{5}$ structure type } \\
\hline Position of metal atom & $x$ & $Y$ & $z$ \\
\hline $\mathrm{Ca}(1 \mathrm{a})$ & 0 & 0 & 0 \\
$\mathrm{Cu}(2 \mathrm{c})$ & $1 / 3$ & $2 / 3$ & 0 \\
$\mathrm{Cu}(3 \mathrm{~g})$ & $1 / 2$ & 0 & $1 / 2$ \\
\hline Interstitial position & & & \\
\hline $3 \mathrm{f}$ & $1 / 2$ & 0 & 0 \\
$4 \mathrm{~h}$ & $1 / 3$ & $2 / 3$ & 0.369 \\
$12 \mathrm{o}$ & 0.204 & 0.408 & 0.354 \\
$12 \mathrm{n}$ & 0.455 & 0 & 0.117 \\
$6 \mathrm{~m}$ & 0.136 & 0.272 & $1 / 2$ \\
\hline
\end{tabular}


Table 2 Enthalpies of formation $(\Delta \mathrm{H}(\mathrm{kJ} /(\mathrm{mol} \mathrm{H})))$ for reaction $\mathrm{YCo}_{5}+1 / 2 \mathrm{H}_{2} \rightarrow \mathrm{YCo}_{5} \mathrm{H}$ obtained from US-PP-PW calculations.

\begin{tabular}{c|c|c|} 
& \multicolumn{2}{|c|}{$\Delta \mathrm{H}(\mathrm{kJ} /(\mathrm{mol} \mathrm{H}))$} \\
\hline Site & $N S P$ & $S P$ \\
\hline $3 \mathrm{f}$ & -18.6 & -4.2 \\
$12 \mathrm{o}$ & 21.1 & 34.0 \\
\hline $12 \mathrm{n}$ & -3.0 & 9.7 \\
$6 \mathrm{~m}$ & -19.1 & -4.6 \\
\hline
\end{tabular}


Table 3 Enthalpies of formation $(\Delta \mathrm{H}(\mathrm{kJ} /(\mathrm{mol} \mathrm{H})))$ for reaction $\mathrm{YCo}_{5}+1 / 4 \mathrm{H}_{2} \rightarrow \mathrm{YCo}_{5} \mathrm{H}_{0.5}$ obtained from US-PP-PW calculations.

\begin{tabular}{c|c|c|} 
& \multicolumn{2}{|c|}{$\Delta \mathrm{H}(\mathrm{kJ} /(\mathrm{mol} \mathrm{H}))$} \\
\hline Site & NSP & $S P$ \\
\hline $3 \mathrm{f}$ & -32.4 & -7.4 \\
$12 \mathrm{o}$ & 28.2 & 35.2 \\
$12 \mathrm{n}$ & -6.8 & 11.4 \\
$6 \mathrm{~m}$ & -32.4 & -7.4 \\
\hline
\end{tabular}

Table 4 Enthalpies of formation $(\Delta \mathrm{H}(\mathrm{kJ} /(\mathrm{mol} \mathrm{H})))$ for reaction $\mathrm{YCo}_{5}+\mathrm{x} / 2 \mathrm{H}_{2} \rightarrow \mathrm{YCo}_{5} \mathrm{H}_{x}$ obtained from US-PP-PW calculations. $\mathrm{H}$ atom is placed in $12 \mathrm{n}$ position.

\begin{tabular}{c|c|c|} 
& \multicolumn{2}{|c|}{$\Delta \mathrm{H}(\mathrm{kJ} /(\mathrm{mol} \mathrm{H}))$} \\
\hline$X$ & $N S P$ & $S P$ \\
\hline 0.25 & -15.6 & -7.4 \\
1.0 & -32.4 & -7.4 \\
& -19.1 & -4.6 \\
\hline
\end{tabular}


Table 5 Crystal structure data obtained for $\beta^{\mathrm{I}}-\mathrm{LaCo}_{5} \mathrm{D}_{3.35}$ phase from neutron diffraction [14].

\begin{tabular}{|c|c|c|c|c|}
\hline \multicolumn{5}{|c|}{ Space group $\mathrm{Cmmm}$} \\
\hline & $a=8.973 \AA$ & $\mathrm{b}=5.413 \AA$ & $\mathrm{c}=4.088 \AA$ & \\
\hline atom & site & $x$ & $y$ & $z$ \\
\hline $\mathrm{La}$ & $2 \mathrm{a}$ & 0.0 & 0.0 & 0.0 \\
\hline Co1 & $4 \mathrm{~g}$ & 0.370 & 0.0 & 0.0 \\
\hline $\mathrm{Co} 2$ & $2 \mathrm{c}$ & 0.0 & 0.5 & 0.5 \\
\hline $\mathrm{Co} 3$ & $4 f$ & 0.25 & 0.25 & 0.5 \\
\hline D1 & $4 e$ & 0.25 & 0.25 & 0.0 \\
\hline D2 & $4 \mathrm{~h}$ & 0.146 & 0.0 & 0.5 \\
\hline
\end{tabular}


Table 6 Crystal structure data obtained for $\beta^{\mathrm{III}}-\mathrm{CeCo}_{5} \mathrm{D}_{2.55}$ phase from neutron diffraction [14].

\begin{tabular}{|c|c|c|c|c|}
\hline \multicolumn{5}{|c|}{ Space group $C c c m$} \\
\hline & $a=8.728 \AA$ & $\mathrm{b}=5.105 \AA$ & $\mathrm{c}=8.146 \AA$ & \\
\hline atom & site & $x$ & $y$ & $z$ \\
\hline $\mathrm{Ce}$ & $4 \mathrm{c}$ & 0.0 & 0.0 & 0.0 \\
\hline Co1 & 81 & 0.354 & 0.944 & 0.0 \\
\hline $\mathrm{Co} 2$ & $4 b$ & 0.5 & 0.0 & 0.25 \\
\hline $\mathrm{Co} 3$ & $8 \mathrm{k}$ & 0.25 & 0.25 & $0.25(\mathrm{a})$ \\
\hline D1 & $4 e$ & 0.25 & 0.25 & 0.0 \\
\hline D2 & $8 g$ & 0.132 & 0.0 & 0.25 \\
\hline
\end{tabular}

(a) - $\mathrm{z}$ coordinate for $8 \mathrm{k}$ site was not provided in [14].

A value of 0.25 was proposed in [20]. 
Table 7 Enthalpies of formation for $\alpha \rightarrow \beta$ transition obtained from US-PP-PW-NSP calculations. Experimental value for $\alpha \rightarrow \beta$ transition obtained in [13] is also provided for comparison.

\begin{tabular}{|c|c|}
\hline \multicolumn{2}{|c|}{$\Delta \mathrm{H}(\mathrm{kJ} /(\mathrm{mol} \mathrm{H}))$} \\
\hline$\Delta \mathrm{H}_{0.0 \rightarrow 3.0}(\mathrm{a})$ & -19.3 \\
\hline$\Delta \mathrm{H}_{0.0 \rightarrow 3.0}(\mathrm{~b})$ & -20.9 \\
\hline$\Delta \mathrm{H}_{0.0 \rightarrow 3.5}(\mathrm{a})$ & -19.5 \\
\hline$\Delta \mathrm{H}_{0.0 \rightarrow 4.0}(\mathrm{a})$ & -19.4 \\
\hline$\Delta \mathrm{H}_{0.25 \rightarrow 3.0}$ (a) & -19.7 \\
\hline$\Delta \mathrm{H}_{0.25 \rightarrow 3.0}(\mathrm{~b})$ & -21.4 \\
\hline$\Delta \mathrm{H}_{0.25 \rightarrow 3.5}$ (a) & -19.9 \\
\hline$\Delta \mathrm{H}_{0.25 \rightarrow 4.0}(\mathrm{a})$ & -19.7 \\
\hline$\Delta \mathrm{H}_{0.5 \rightarrow 3.0}(\mathrm{a})$ & -16.7 \\
\hline$\Delta \mathrm{H}_{0.5 \rightarrow 3.0}(\mathrm{~b})$ & -18.6 \\
\hline$\Delta \mathrm{H}_{0.5 \rightarrow 3.5}$ (a) & -17.4 \\
\hline$\Delta \mathrm{H}_{0.5 \rightarrow 4.0}(\mathrm{a})$ & -17.6 \\
\hline experiment [13] & -15.2 \\
\hline
\end{tabular}

(a) $\beta^{\mathrm{I}}-\mathrm{LaCo}_{5} \mathrm{D}_{3.35}$ structure [14] was employed to model the corresponding $\mathrm{YCo}_{5} \mathrm{H}_{\mathrm{x}}$ composition.

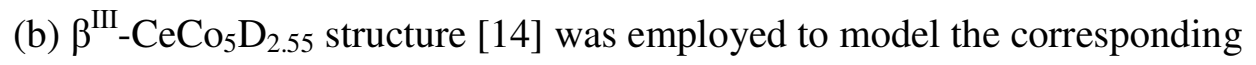
$\mathrm{YCo}_{5} \mathrm{H}_{\mathrm{x}}$ composition. 
Table 8 Enthalpies of formation for $\alpha \rightarrow \beta$ transition obtained from US-PP-PW-SP calculations. Experimental value for $\alpha \rightarrow \beta$ transition obtained in [13] is also provided for comparison.

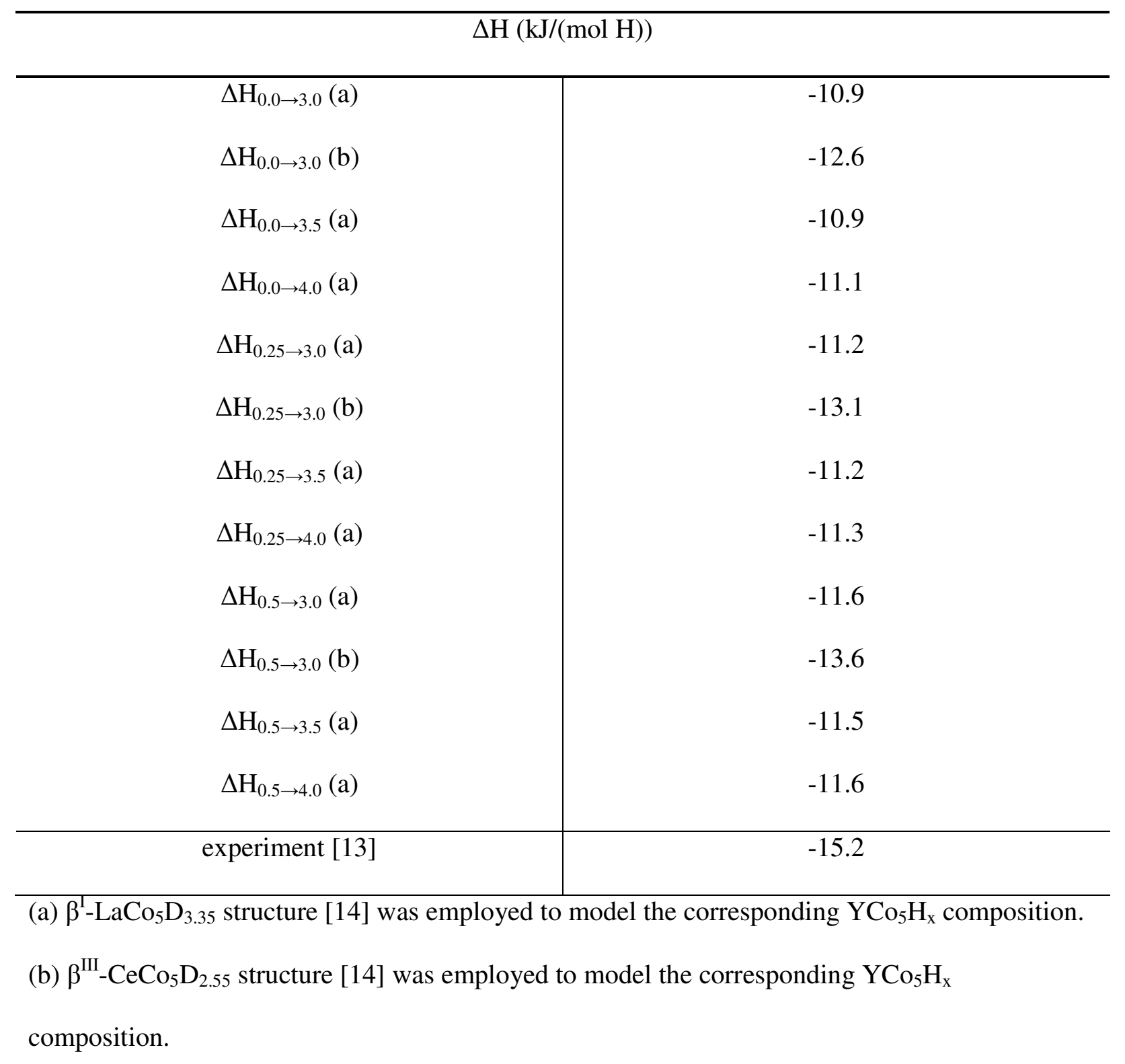


Table 9 Calculated spin magnetic moments obtained from US-PP-PW-SP calculations. Some previous experimental and theoretical results are provided as well.

Magnetic moments are provided per one $\mathrm{YCo}_{5}$ formula unit. Abbreviations: $\mathbf{M}_{\mathrm{s}}$-total spin magnetic moment, $\mathbf{M}_{\text {tot-total magnetic moment. }}$

\begin{tabular}{|c|c|c|}
\hline Compound & $\mathrm{M}_{\mathrm{s}}\left(\mu_{\mathrm{B}} / \mathrm{YCo}_{5}\right.$ f.u. $)$ & $\begin{array}{l}\text { Previous theoretical results } \\
\mathrm{M}_{\mathrm{s}}\left(\mu_{\mathrm{B}} / \mathrm{YCo}_{5} \text { f.u. }\right)\end{array}$ \\
\hline $\mathrm{YCO}_{5}$ & 7.22 & $\begin{array}{l}7.06[17], 6.78[18], 6.84[18], \\
6.90[18], 7.32[16]\end{array}$ \\
\hline $\mathrm{YCo} \mathrm{H}_{0.25}(12 \mathrm{n})$ & 7.13 & \\
\hline $\mathrm{YCo} \mathrm{H}_{0.5}(3 \mathrm{f}, 4 \mathrm{~h}, 12 \mathrm{o}, 12 \mathrm{n}, 6 \mathrm{~m})$ & $7.03,6.90,6.98,7.03,7.16$ & \\
\hline $\mathrm{YCo} 5 \mathrm{H}(3 \mathrm{f}, 4 \mathrm{~h}, 12 \mathrm{o}, 12 \mathrm{n}, 6 \mathrm{~m})$ & $6.96,6.51,6.71,6.93,7.02$ & \\
\hline $\mathrm{YCo} \mathrm{H}_{3}(\mathrm{a})$ & 6.49 & \\
\hline $\mathrm{YCo} \mathrm{H}_{3}(\mathrm{~b})$ & 6.54 & \\
\hline $\mathrm{YCo} \mathrm{H}_{3.5}$ (a) & 6.90 & \\
\hline $\mathrm{YCo} \mathrm{H}_{4}(\mathrm{a})$ & 7.07 & \\
\hline & $\mathrm{M}_{\mathrm{tot}}\left(\mu_{\mathrm{B}} / \mathrm{YCo}_{5}\right.$ f.u. $)$ & \\
\hline $\begin{array}{l}\mathrm{YCo}_{5} \text { (experimental) [15] } \\
\alpha \text {-phase (experimental) [15] } \\
\beta \text {-phase (experimental) [15] }\end{array}$ & $\begin{array}{l}7.76 \\
7.21 \\
6.25\end{array}$ & \\
\hline
\end{tabular}

(a) $\beta^{\mathrm{I}}-\mathrm{LaCo}_{5} \mathrm{D}_{3.35}$ structure [14] was employed to model the corresponding $\mathrm{YCo}_{5} \mathrm{H}_{\mathrm{x}}$ composition.

(b) $\beta^{\mathrm{III}}-\mathrm{CeCo}_{5} \mathrm{D}_{2.55}$ structure [14] was employed to model the corresponding $\mathrm{YCo}_{5} \mathrm{H}_{\mathrm{x}}$ composition. 
Table 10 Calculated values of the total spin magnetic moment per formula unit of $\mathrm{YCo}_{5}$ and $\mathrm{YCo}_{5} \mathrm{H}_{\mathrm{x}} \cdot$ Present results are obtained from FP(L)APW + lo calculations.

Some previous experimental and theoretical results are provided as well.

Abbreviations: $\mathbf{M}_{\mathrm{s}}$-total spin magnetic moment, $\mathbf{M}_{\text {tot }}$-total magnetic moment.

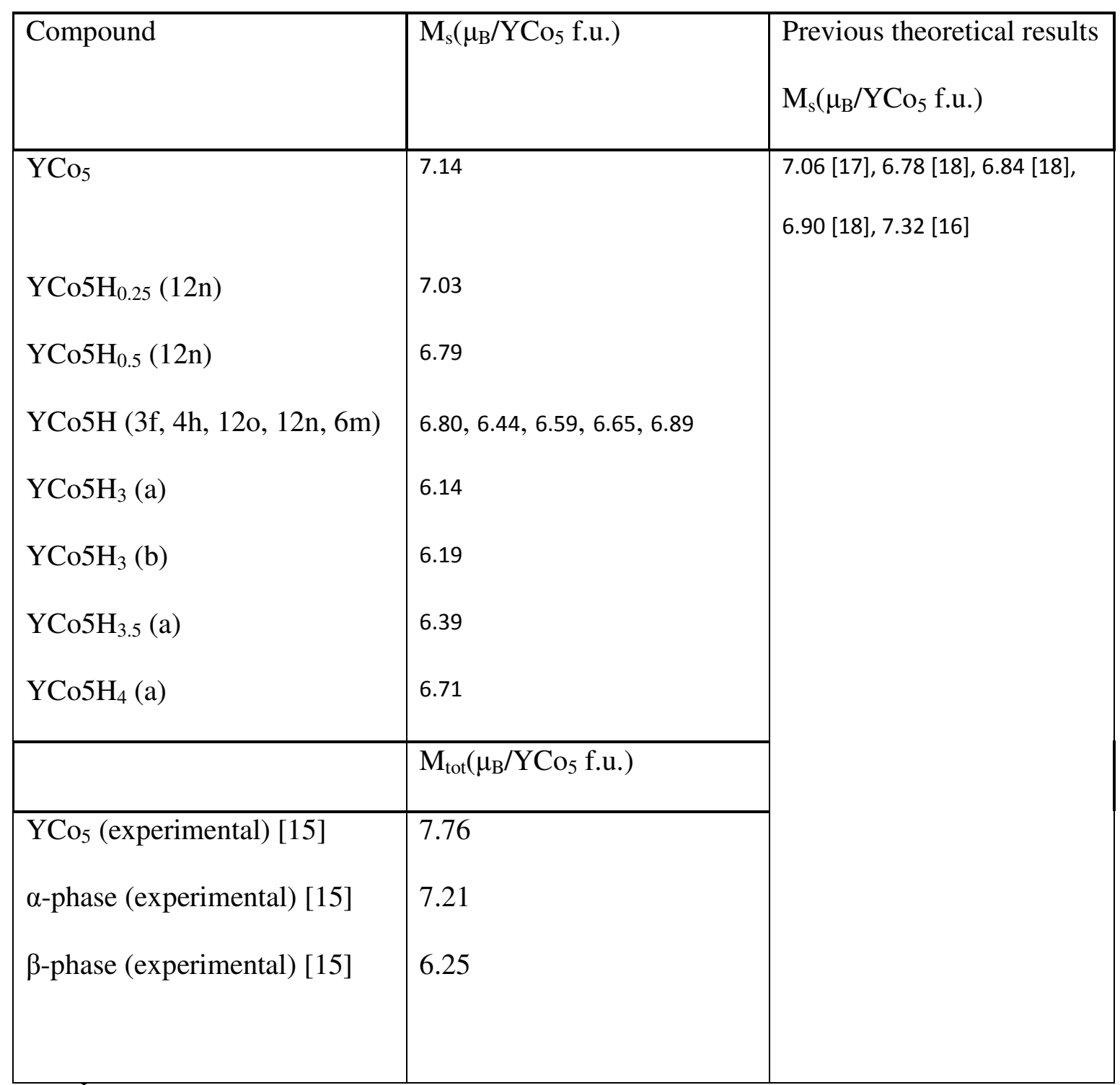

(a) $\beta$-LaCo $\mathrm{D}_{3.35}$ structure [14] was employed to model the corresponding $\mathrm{YCo}_{5} \mathrm{H}_{\mathrm{x}}$ composition.

(b) $\beta^{\mathrm{III}}-\mathrm{CeCo}_{5} \mathrm{D}_{2.55}$ structure [14] was employed to model the corresponding $\mathrm{YCo}_{5} \mathrm{H}_{\mathrm{x}}$ composition. 
Table 11 Calculated spin magnetic moments on $\mathrm{Co}$ atoms in $\mathrm{YCO}_{5}$ and its hydrides. Present results are obtained from FP(L)APW + lo calculations. Some previous experimental and theoretical results are provided as well.

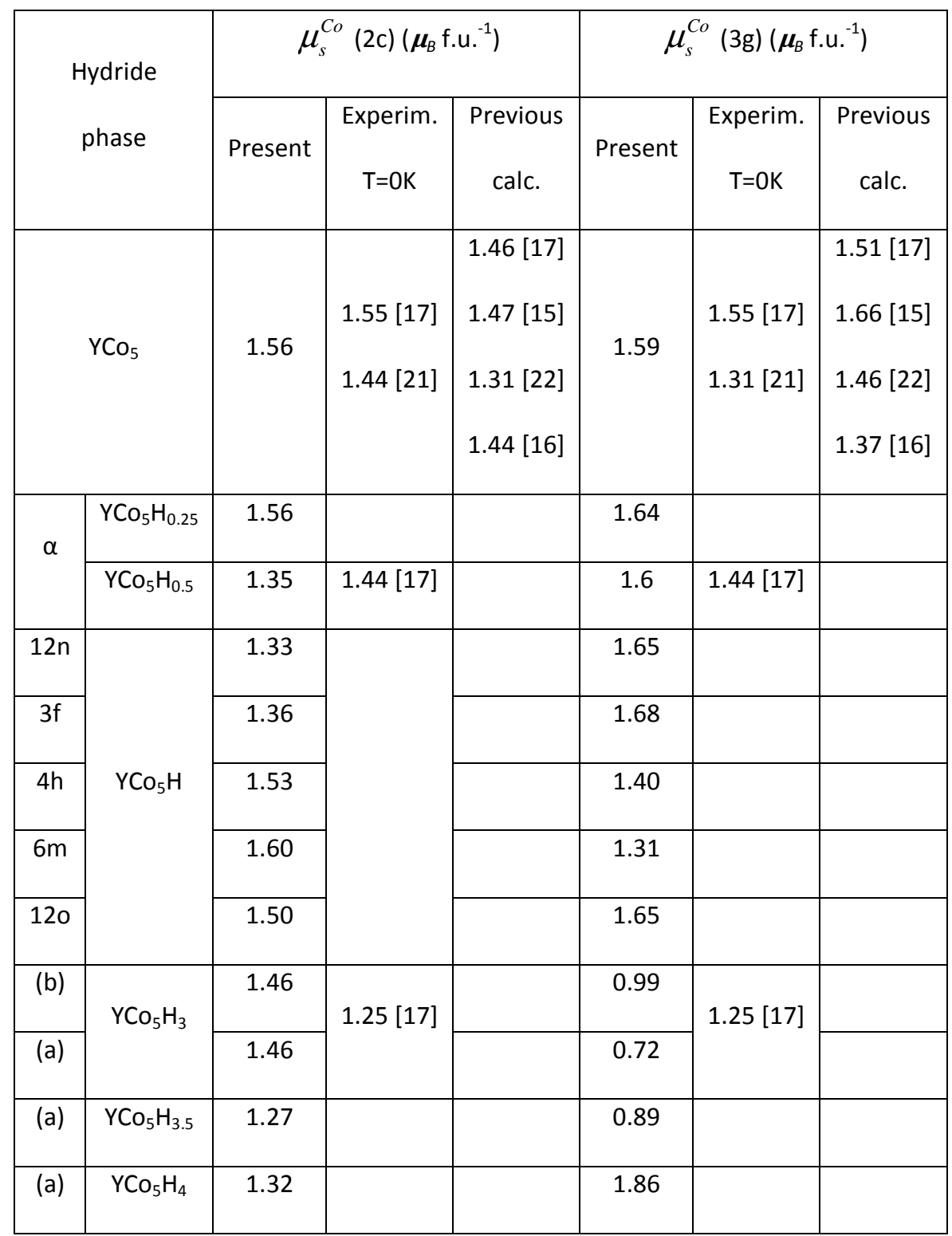

(a) $\beta^{\mathrm{I}}$-LaCo $\mathrm{D}_{3.35}$ structure [14] was employed to model the corresponding $\mathrm{YCo}_{5} \mathrm{H}_{\mathrm{x}}$ composition.

(b) $\beta^{\mathrm{III}}-\mathrm{CeCo}_{5} \mathrm{D}_{2.55}$ structure [14] was employed to model the corresponding $\mathrm{YCo}_{5} \mathrm{H}_{\mathrm{x}}$ composition. 
Table 12 Calculated orbital magnetic moments on $\mathrm{Co}$ atoms in $\mathrm{YCO}_{5}$ and its hydrides. Present results are obtained from FP(L)APW + lo calculations. Some previous experimental and theoretical results are provided as well.

\begin{tabular}{|c|c|c|c|c|c|c|}
\hline \multirow[t]{2}{*}{ compound } & \multicolumn{3}{|c|}{$\mu_{l}^{C o}(2 \mathrm{c})\left(\mu_{B}\right.$ atom $\left.^{-1}\right)$} & \multicolumn{3}{|c|}{$\mu_{l}^{C o}(3 \mathrm{~g})\left(\mu_{B}\right.$ atom $\left.^{-1}\right)$} \\
\hline & $\mathrm{m}_{\text {orb }}$ & $\begin{array}{l}\text { Experim. } \\
\mathrm{T}=0 \mathrm{~K}\end{array}$ & $\begin{array}{l}\text { Previous } \\
\text { calc. }\end{array}$ & $m_{\text {orb }}$ & $\begin{array}{l}\text { Experim. } \\
\mathrm{T}=0 \mathrm{~K}\end{array}$ & $\begin{array}{l}\text { Previous } \\
\text { calc. }\end{array}$ \\
\hline $\mathrm{YCO}_{5}$ & 0.11 & $0.46[19]$ & $\begin{array}{l}0.1 \text { [19], } \\
0.14 \text { [16], } \\
0.11 \text { [17] }\end{array}$ & 0.1 & $0.28[19]$ & $\begin{array}{l}0.13 \text { [19], } \\
0.1[16], \\
0.13 \text { [17] }\end{array}$ \\
\hline $\mathrm{YCO}_{5} \mathrm{H}_{0.25}(12 \mathrm{n})$ & 0.1 & & & 0.11 & & \\
\hline $\mathrm{YCO}_{5} \mathrm{H}_{0.5}(12 \mathrm{n})$ & 0.12 & & & 0.09 & & \\
\hline $\mathrm{YCO}_{5} \mathrm{H}(12 \mathrm{n})$ & 0.15 & & & 0.08 & & \\
\hline $\mathrm{YCO}_{5} \mathrm{H}_{3}(\mathrm{~b})$ & 0.11 & & & 0.04 & & \\
\hline $\mathrm{YCO}_{5} \mathrm{H}_{4}$ (a) & 0.08 & & & 0.04 & & \\
\hline
\end{tabular}

(a) $\beta^{\mathrm{I}}-\mathrm{LaCo}_{5} \mathrm{D}_{3.35}$ structure [14] was employed to model the corresponding $\mathrm{YCo}_{5} \mathrm{H}_{\mathrm{x}}$ composition.

(b) $\beta^{\mathrm{III}}-\mathrm{CeCo}_{5} \mathrm{D}_{2.55}$ structure [14] was employed to model the corresponding $\mathrm{YCo}_{5} \mathrm{H}_{\mathrm{x}}$ composition. 
Table 13 Electric field gradients and asymmetry parameters on Y, Co-2c, and Co-3g atoms in $\mathrm{YCo}_{5} \mathrm{H}_{\mathrm{x}}$ obtained from $\mathrm{FP}(\mathrm{L}) \mathrm{APW}+\mathrm{lo}$ calculations.

\begin{tabular}{|c|c|c|c|c|c|c|c|}
\hline & \multirow{2}{*}{$\begin{array}{c}\text { Hydride } \\
\text { phase }\end{array}$} & \multicolumn{2}{|l|}{$\mathrm{Y}$} & \multicolumn{2}{|c|}{ Co-2c } & \multicolumn{2}{|c|}{ Co-3g } \\
\hline & & $\begin{array}{c}V_{z z}^{t o t} \\
\left(10^{21} \mathrm{Vm}^{-2}\right)\end{array}$ & $\eta$ & $\begin{array}{c}V_{z z}^{t o t} \\
\left(10^{21} \mathrm{Vm}^{-2}\right)\end{array}$ & $\eta$ & $\begin{array}{c}V_{z z}^{t o t} \\
\left(10^{21} \mathrm{Vm}^{-2}\right)\end{array}$ & $\eta$ \\
\hline & $\mathrm{YCO}_{5}$ & 6.243 & 0 & -3.521 & 0 & 4.504 & 0.77 \\
\hline \multirow{2}{*}{$\alpha$} & $\mathrm{YCO}_{5} \mathrm{H}_{0.25}(12 \mathrm{n})$ & 6.108 & 0.07 & -3.25 & 0.588 & 2.376 & 0.8 \\
\hline & $\mathrm{YCO}_{5} \mathrm{H}_{0.5}(12 \mathrm{n})$ & 5.526 & 0.41 & -2.641 & 0.45 & 3.486 & 0.91 \\
\hline $12 n$ & \multirow{5}{*}{$\mathrm{YCO}_{5} \mathrm{H}$} & 6.139 & 0.58 & -1.731 & 0.66 & 4.771 & 0.91 \\
\hline $3 f$ & & 6.437 & 0.5 & -1.914 & 0.61 & -2.786 & 0.09 \\
\hline $4 \mathrm{~h}$ & & 6.048 & 0 & -5.088 & 0.01 & -4.756 & 0.53 \\
\hline $6 m$ & & -5.015 & 0.66 & -4.119 & 0.07 & 2.801 & 0.86 \\
\hline 120 & & 6.413 & 0.04 & -3.78 & 0.07 & -3.102 & 0.67 \\
\hline (b) & \multirow{2}{*}{$\mathrm{YCO}_{5} \mathrm{H}_{3}$} & 2.517 & 0.72 & -3.279 & 0.51 & 4.453 & 0.25 \\
\hline (a) & & -4.18 & 0.46 & -2.45 & 0.89 & 3.825 & 0.2 \\
\hline (a) & $\mathrm{YCO}_{5} \mathrm{H}_{3.5}$ & -4.286 & 0.31 & 1.078 & 0.27 & 3.317 & 0.49 \\
\hline (a) & $\mathrm{YCO}_{5} \mathrm{H}_{4}$ & -4.77 & 0.07 & 1.117 & 0.39 & 2.185 & 0.167 \\
\hline
\end{tabular}

(a) $\beta^{\mathrm{I}}$-LaCo ${ }_{5} \mathrm{D}_{3.35}$ structure [14] was employed to model the corresponding $\mathrm{YCo}_{5} \mathrm{H}_{\mathrm{x}}$ composition.

(b) $\beta^{\mathrm{III}}-\mathrm{CeCo}_{5} \mathrm{D}_{2.55}$ structure [14] was employed to model the corresponding $\mathrm{YCo}_{5} \mathrm{H}_{\mathrm{x}}$ composition. 
Table 14 Calculated hyperfine fields on $\mathrm{Y}$, and two unequivalent $\mathrm{Co}$ atoms in $\mathrm{YCo}_{5}$ and $\mathrm{YCO}_{5} \mathrm{H}_{\mathrm{x}} \cdot$ Results are obtained from $\mathrm{FP}(\mathrm{L}) \mathrm{APW}+$ lo calculations.

\begin{tabular}{|c|c|c|c|c|}
\hline & Hydride & Y & Co-2c & Co-3g \\
\hline & phase & $B_{h f}(\mathrm{~T})$ & $B_{h f}(\mathrm{~T})$ & $B_{h f}(\mathrm{~T})$ \\
\hline & $\mathrm{YCO}_{5}$ & -13.35 & -12.5 & -19.1 \\
\hline & $\mathrm{YCO}_{5} \mathrm{H}_{0.25}(12 \mathrm{n})$ & -13.44 & -13.38 & -20.0 \\
\hline & $\mathrm{YCO}_{5} \mathrm{H}_{0.5}(12 \mathrm{n})$ & -10.09 & -18.38 & -19.26 \\
\hline $12 n$ & $\mathrm{YCO}_{5} \mathrm{H}$ & -8.15 & -15.95 & -19.71 \\
\hline (b) & & -8.47 & -16.58 & -15.86 \\
\hline (a) & & -8.23 & -15.32 & -14.19 \\
\hline (a) & $\mathrm{YCO}_{5} \mathrm{H}_{3.5}$ & -7.27 & -15.7 & -15.96 \\
\hline (a) & $\mathrm{YCO}_{5} \mathrm{H}_{4}$ & -6.82 & -14.38 & -18.11 \\
\hline
\end{tabular}

(a) $\beta^{\mathrm{I}}-\mathrm{LaCo}_{5} \mathrm{D}_{3.35}$ structure [14] was employed to model the corresponding $\mathrm{YCo}_{5} \mathrm{H}_{\mathrm{x}}$ composition.

(b) $\beta^{\mathrm{III}}-\mathrm{CeCo}_{5} \mathrm{D}_{2.55}$ structure [14] was employed to model the corresponding $\mathrm{YCo}_{5} \mathrm{H}_{\mathrm{x}}$ composition. 